Artigos

\title{
Contribuições de Jürgen Habermas para o debate epistemológico iniciado por Karl Popper e Theodor Adorno
}

\section{Jürgen Habermas's contributions to the epistemological debate initiated by Karl Popper and Theodor Adorno}

Rubia de Araujo Ramos*

Resumo: O Objetivo deste artigo consiste em apresentar fundamentos da proposta epistemológica de Jürgen Habermas, identificados em obras precedentes à sua Teoria do agir comunicativo. A partir de Teoria analítica da ciência e dialética será explorada a proposta do autor, tendo percorrido antecipadamente pela querela entre Popper e Adorno; posteriormente busca-se analisar como Habermas, em debate com seus contemporâneos, retrata sua proposta em Técnica e ciência como ideologia, considerado um marco para a Escola de Frankfurt.

Palavras-chaves: Popper. Adorno. Positivismo. Dialética. Habermas.

Abstract: The purpose of this article is to introduce foundations of the epistemological proposal of Jürgen Habermas, which are found in his works previous to The theory communicative action. The text addresses the dispute between Popper and Adorno and then focuses on Habermas' proposal based on The analytical theory of science and dialectics. Finally, it discusses how Habermas portrays, in his debate with others contemporary authors, his proposal at Technology and science as "ideology", considered a landmark for Frankfurt School.

Keywords: Popper. Adorno. Positivism. Dialectic. Habermas.

\footnotetext{
* Doutoranda pelo PPG em Sociologia da Universidade Estadual de Campinas (Unicamp, Campinas, SP, Brasil), onde integra o grupo de pesquisa Teoria Crítica e Sociologia <ramos.arubia@gmail.com>.
} 


\section{Introdução}

O debate entre Karl Popper e Theodor Adorno sobre os fundamentos epistemológicos do positivismo e da dialética, promovido pela Sociedade de Sociologia Alemã no ano de 1961 em Tuebingen, deu início a um conjunto de produções intelectuais dedicadas ao campo do conhecimento nas Ciências Sociais. ${ }^{1}$ Em seu texto Lógica das ciências sociais, Popper (1978a) expôs vinte e sete teses sobre a epistemologia das Ciências Sociais, abordando, entre outros temas, a objetividade e a neutralidade do conhecimento científico, entendendo que estas residem no teste empírico de falseabilidade das teorias. ${ }^{2}$

A polêmica sobre as diferenças entre Popper e os positivistas tradicionais foi tratada por vários intelectuais, entre eles Freitag (1986, p.44-45) que, apoiada em Horkheimer (1983 [1937]), observa que a postura positivista de Popper estaria na defesa do método, da "lógica situacional", isto é, na defesa de uma teoria apoiada num sistema de sentenças e hipóteses gerais - razão por que foi considerado um herdeiro do positivismo lógico, buscando superá-lo ao propor a substituição do princípio de verificabilidade pelo princípio da

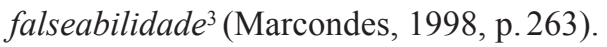

Em resposta às críticas de Habermas e de Adorno, Karl Popper (1978b, p. 48) diz:

Eu lutei contra a imitação das ciências naturais pelas ciências sociais e pelo ponto de vista de que a epistemologia positivista é inadequada até mesmo em sua análise das ciências naturais as quais, de fato, não são "generalizações cuidadosas da observação", como se crê usualmente mas são essencialmente especulativas e ousadas; além disso eu pensei, por mais de 38 anos, que todas as observações estão impregnadas de teoria e que sua função principal é de verificar e refutar, mais do que provar nossas teorias.

\footnotetext{
${ }^{1}$ Ralf Dahrendorf, organizador do debate e do livro que o registra, em sua análise "Anotaciones a la discusíon de las ponencias de Karl R. Popper y Theodor W. Adorno" (1972 [1969], p. 139146) tratou de aparentes concordâncias entre os debatedores, sobre a predileção pela categoria crítica, e principalmente as diferenças quanto às posições epistemológicas e lógico-científicas, bem como princípios morais de relevância política. Posteriormente, no Brasil, Barbara Freitag (1986, p.43-52) apresenta um conjunto de autores e obras que fizeram parte do debate entre teóricos positivistas e teóricos críticos. Desse conjunto, destaco importantes contribuições da Teoria Crítica: A ideologia da sociedade industrial (1973 [1964]), de Marcuse; e Dialética negativa (1965), de Adorno.

${ }^{2}$ Nessas teses, Popper apresenta sua crítica ao empirismo clássico do Círculo de Viena, o qual defendia o conhecimento factual como resultado de observações e verificações empíricas de proposições.

3 A respeito dos princípios de verificabilidade e falseabilidade - o método do Círculo de Viena e o método proposto por Karl Popper, Sauer (1996), Pasquinelli (1983) e Barreto (2001) publicaram artigos significativos. Barreto em especial sobre as diferenças e aproximações.
} 
Angela Ganem (2012, p. 90) ao destacar a preocupação do epistemólogo em ser reconhecido como um crítico do positivismo, não deixa de tratar dessa questão como uma controvérsia, um "reformismo epistemológico". Tal aspecto também pode ser encontrado em Giddens (1980), quando este apresenta divergências entre Popper e os positivistas lógicos, mas também semelhanças visíveis, como a convicção de que o conhecimento científico seria o conhecimento mais seguro e fidedigno que o homem poderia aspirar é partilhada junto com a caracterização da ciência pelo procedimento, isto é, "a ciência se separa das outras formas de tradição na medida em que suas teorias e constatações podem ser submetidas à prova empírica e, portanto, à refutação potencial" (Giddens, 1980, p. 345).

Pelas críticas, Popper não rompe por completo com preceitos do positivismo lógico, e isso também pode ser percebido, como mostra Giddens, pela relação entre Popper e membros do próprio Círculo de Viena, os quais consideraram sua primeira obra Logik der Forschung ${ }^{4}$ um trabalho de acordo com a perspectiva do positivismo lógico. Apesar de Popper reivindicar-se desde esta obra um crítico do Círculo de Viena, e destacar suas diferenças em relação a qualquer tipo de positivismo, o aspecto controverso marcou sua trajetória, o epistemólogo ficou sendo identificado, por muitos, como um defensor de um tipo de positivismo mais rebuscado.

A defesa do método aproximaria Popper de uma Teoria Tradicional, justificada pela atribuição de objetividade do conhecimento e de sua neutralidade. Em suas teses, Popper (1978a, p. 26) credita ao método dedutivo a qualidade de uma ciência crítica, conforme expressa em sua décima-sexta tese: "A lógica dedutiva é a teoria da validade das deduções lógicas ou da relação de consequência lógica. [...] se as premissas de uma dedução válida são verdadeiras, então a conclusão deve também ser verdadeira. Isto também pode ser expresso como se segue. A lógica dedutiva é a teoria da transmissão da verdade, das premissas à conclusão".

Entre os temas que animaram esse debate, a noção de crítica (Freitag, 1986, p. 51), por exemplo, que para Popper estaria relacionada ao método dedutivo de práticas com testes de falseabilidade de hipóteses, para Adorno significa aceitar a existência de contradição em qualquer processo do conhecimento. Dahrendorf (1972) fala em predileção dos dois debatedores pela categoria crítica, observando que em Adorno esta se localiza no desenvolvimento das contradições da sociedade mediante o conhecimento das mesmas. Sob a

\footnotetext{
${ }^{4}$ Trabalho de 1933, originalmente publicada em alemão. No Brasil foi traduzido como A lógica da pesquisa cientifica pela editora Cultrix.
} 
influência epistemológica e a concepção da teoria crítica de Horkheimer (1983 [1937]), Adorno qualifica Popper como positivista, em razão deste priorizar o método e não o objeto como determinante do processo do conhecimento e da objetividade do mesmo (Adorno, 1980). ${ }^{5}$ Para essa perspectiva, Popper não considera as contradições do objeto e acaba por reduzir problemas do mundo social em problemas de caráter epistemológico, enfatizando mais problemas formais do que questões factuais apontadas pelo pensamento dialético. Nesse sentido, a noção de verdade também é distinta. Se para uma epistemologia a verdade é obtida por meio da permanência de regras da lógica formal e situacional (método popperiano), para a outra epistemologia, de Adorno e dos teóricos críticos da Escola de Frankfurt, a verdade só pode ser entendida quando a crítica passa por todo o processo do conhecimento, isto é, quando se questiona as hipóteses, os conceitos, a escolha do objeto e a construção do próprio conhecimento.

Toda a crítica de Adorno expressa a preocupação do paradigma dialético, ou seja, a preocupação em identificar limitações e armadilhas da razão iluminista, as contradições da modernidade, do uso da razão instrumental, bem como a necessidade de retomar a razão emancipatória e pensar criticamente o presente, trazendo conteúdos propositivos para melhores condições futuras, e buscar os potenciais de transformação que foram reprimidos no passado, e que, portanto, não poderiam ser revelados por uma teoria totalizante.

Entre as armadilhas da ciência positiva, para Adorno, as ausências de questionamento sobre as próprias bases do pensamento, sobre sua origem e a postura que desvincula objeto e o todo social e político, faz da ciência a razão instrumental a serviço de interesses de dominação. Adorno chama atenção para a falta de reflexão e crítica sobre as condições impostas nas relações de produção, como a divisão do trabalho, que também se estende para as ciências na forma de conhecimentos especializados ou subáreas do saber. Nesse sentido, a ciência moderna positiva acaba por naturalizar o funcionamento sistêmico da sociedade, ao passo que a ciência como um todo não está livre de relações de conveniência e de dominação, condicionada pela lógica capitalista, o saber científico passa a atender interesses políticos e econômicos.

\footnotetext{
${ }_{5}^{5}$ É importante salientar que estamos lidando com a perspectiva de que Popper propõe um tipo de positivismo. Tal postura se deve ao objetivo central desta exposição, sobre as contribuições de Jürgen Habermas para o debate em questão, bem como as possíveis influências desse debate para a construção da proposta epistemológica de Habermas em seus primeiros trabalhos. Desse modo, ainda que se tome nota das críticas de Popper ao Círculo de Viena e suas diferenças, é necessário partir da perspectiva dialética, adotada por Habermas, para que a construção do pensamento deste autor seja melhor compreendida.
} 
Dahrendorf observou que nem Popper e nem Adorno trataram da questão do juízo de valor na construção do conhecimento, tema que naquele momento era urgente e aguardado. Outro ponto de crítica ao modo como os expositores conduziram o debate se refere à falta de precisão das posições lógico-científicas, à falta de análise detalhada da relação entre teoria e empiria, análise e investigação factual, deixando questões abertas e expectativas frustradas (Dahrendorf, 1972, p.146). Pontos em comum se destacaram sobre o problema da clivagem entre ciências da natureza e ciências do espírito, parecendo, a princípio, que Popper e Adorno estavam inclinados a se apegar a essa distinção, mas aspectos distintos e até contraditórios apareceram em suas argumentações a respeito da construção do pensamento crítico (Dahrendorf, 1972, p. 141), conforme parte deles apresentados acima.

A querela entre os modelos epistemológicos do positivismo e da dialética nas ciências sociais mostrou que, para além do que foi brevemente apresentado até aqui, abriu espaço para outra discussão em torno da relação entre teoria e prática. Na dialética defendida por Adorno, a teoria se coloca propositiva a tratar de melhores condições futuras - objetivo este que remete à prática. $\mathrm{O}$ racionalismo crítico de Popper, por sua vez, apresenta sua prática limitada à atuação técnica, ao conhecimento especializado, e nesse sentido, o poder de atuação e o conhecimento da realidade estariam nas mãos da sociedade técnica científica. E é nesse contexto que Habermas entra para o debate, e contribuindo para a discussão de alguns conceitos recorrentes da ciência epistemológica, bem como para o debate sobre o papel das Ciências Sociais e sua relação com as Ciências Naturais.

\section{Contribuições de Habermas à polêmica entre Popper e Adorno}

Em Teoria analítica da ciência e dialética, Habermas (1980 [1965]) buscou desenvolver sua análise do debate positivista na sociologia alemã, demonstrando, desde esse período, interesse pelas diferentes formas de conhecimento nas Ciências Sociais (Bernstein, 1994, p. 16). ${ }^{6}$ Para seu estudo crítico e compreensivo da modernidade social e cultural, Habermas partiu do princípio de que as formas de conhecimento fazem parte de processos sociais, buscando fazer da teoria do conhecimento uma teoria social, e com essa proposta, dedicou-se a diferentes aspectos do debate teórico em torno de

${ }^{6}$ Richard J. Bernstein (1994, p. 20) observa que a proposta habermasiana de repensar os processos de racionalização tem sua origem em Max Weber, cuja ascese metodológica seria em si mesma uma expressão de suas análises metodológicas. 
questões epistemológicas nas Ciências Sociais, incluindo as divergências entre a ciência social analítica e a ciência social dialética.

Partindo da concepção de Adorno (1962) para compreender o todo social e suas partes, Habermas se põe contrário à epistemologia de Popper e suas bases na filosofia dedutiva. Entendendo a totalidade pela perspectiva dos antagonismos e pela interdependência entre esta e os elementos que a compõem, a compreensão da realidade dependeria, segundo esse modelo epistemológico, das especificidades da sociedade e de sua totalidade, que não é a soma das partes, das especificidades. Ao refletir sobre as diferenças entre o que chama de sociologia formal, limitada ao conceito funcionalista de sistema, e a sociologia no âmbito dialético, vinculada ao conceito dialético de totalidade, ele se propõe a entender os dois modelos epistemológicos debatidos por Popper e Adorno. E embora reconheça a crítica de Popper sobre os pressupostos empiricistas do positivismo analítico, entende que as questões levantadas por Popper se vinculam à ciência positiva, em razão de adotar a ideia de objetividade da ciência empírico-analítica, a qual sugere que teoria científica representa fatos, impedindo a autonomia destes e testando apenas teorias (Habermas, 1972).

Habermas trata de resíduos positivistas na epistemologia de Karl Popper e de dificuldades de autocrítica da ciência social empírica (Keuth, 2015, p. 163) a respeito dos limites de Popper em questionar as bases de seu próprio pensamento, uma vez que o autoentendimento da ciência social empírica depende da filosofia analítica da ciência. ${ }^{7}$ Embora tenha se imputado a tarefa de explorar os dois modelos epistemológicos em questão, a própria abordagem com que Habermas inicia seu texto indica que sua compreensão científica da discussão positivista não esteve livre da totalidade dialética e de interesses, haja vista que defende abertamente o modelo epistemológico dialético e demonstra por si mesmo a impossibilidade de neutralidade axiológica de uma teoria. Sendo assim, Habermas trata do modelo de Popper como positivista, em sentido amplo, e constrói seus argumentos a partir de quatro diferenças básicas entre a ciência social formal e a ciência social dialética.

A primeira diferença diz respeito à relação entre teoria e realidade. $\mathrm{O}$ conceito de sistema, muito comum na visão científico-experimental da filosofia analítica, segundo Habermas, só conseguiria tratar de relações no plano formal, cuja ontologia não se confunde com as interações comportamentais da realidade vivida. Isso equivale dizer que o conceito central na filosofia analítica só consegue retratar categorias científicas previamente ordenadas,

\footnotetext{
${ }^{7}$ Herbert Keuth (2015) faz uma interessante abordagem das aporias das propostas de Popper e de Habermas.Eleobservaqueindependentementedea Teoria Crítica conseguircumprirseusobjetivos de uma teoria propositiva e ética, ela proporcionou meios eficientes de propaganda política.
} 
isto é, a teoria é previamente definida por lógicas formais, de acordo com as determinações científicas de análise dos enunciados e de cálculos de aplicação que determinam a aplicabilidade da teoria à diversidade do real. Desse modo, a ciência social formal acaba por adequar o objeto às categorias científicas, e os objetos ou reflexões que não se enquadram ou que não são previstos pela teoria vigente acabam no plano do inadmissível.

Contrariando essa postura, o método dialético desconstrói a ideia de que os homens, incluindo os produtores de conhecimento, adotam uma postura neutra sobre a realidade socialmente construída. Habermas duvida da capacidade da filosofia empírico-analítica de alcançar o conhecimento de "esferas isoladas do social ou levar-nos ao domínio técnico de determinadas magnitudes sociais no mesmo nível alcançado pelas ciências naturais" (Habermas, 1980, p. 279). Ele relaciona essa abordagem epistemológica ao que chama de "falsificação do objeto", em outros termos, trata-se da limitação do objeto e de sua estrutura em defesa de uma metodologia totalizante.

$\mathrm{O}$ esforço de Habermas registra sua preocupação com a percepção científica da totalidade. Uma questão já presente em Adorno. Ele entende que toda pesquisa científica está inserida na totalidade social. Esta ideia confronta a lógica positivista da liberdade do cientista social para a escolha de seus métodos e modelos científicos. Sendo assim, o objeto, o método, as hipóteses, e tudo mais que o cientista dispõe, são fornecidos em alguma medida pela totalidade social, em que a própria pesquisa estaria na condição de uma possibilidade gerada no contexto em estudo; o conhecimento estaria limitado pela esfera social. Trata-se da dimensão político-cultural do conhecimento enquanto processo de construção social.

O segundo elemento de diferença refere-se ao tema da relação entre teoria e objeto, que varia de acordo com a relação entre teoria e experiência. No caso da ciência empírico-analítica não importa quem é o sujeito da pesquisa, pois a experiência é sempre a mesma, aquela que determina o comportamento do pesquisador por regras abstratas; pela dedução chega-se às hipóteses que são rigorosamente testadas no plano empírico. Para o modelo oposto, a ciência dialética, a identificação entre teoria e uma experiência específica torna-se inviável. A orientação teórica está sempre ligada ao processo social, onde a experiência dependerá do conteúdo pré-científico acumulado pelo pesquisador - formação cultural e elementos subjetivos do mundo da vida (cf. Schutz, 1962, p.4ss) e do objeto também situado no mesmo processo. Portanto, ao problematizar a questão da experiência, a teoria a ser construída, os conceitos e categorias formais a serem utilizados terão que adequar-se ao objeto predeterminado, e não o contrário. 
“A relação entre a teoria e a experiência é determinante da relação entre a teoria e a história" (Habermas, 1980, p.281). Este é o terceiro ponto, no qual Habermas trata do controle de validade das hipóteses legais - método da ciência empírico-analítica de contrastar suas teorias explicativas. Tal método, a partir da análise de Habermas, acaba por determinar o material histórico; ele subordina fenômenos reais a leis precedentes com base numa lógica objetiva e generalizante, e faz previsões para situações específicas passando por cima de especificidades. Suas explicações objetivas eliminam qualquer vínculo com a hermenêutica subjetiva compreensiva.

Do ponto de vista dialético, a ciência social formal, ao se utilizar de empirismo e verificabilidade de hipóteses, acaba por reificar leis históricas. Torna-se problemático aceitar "leis históricas peculiares" como método que estabelece leis para fundamentar uma análise de um historiador, quando os fundamentos da dialética indicam a postura de não reunir situações e funções específicas e contextos isolados, entendendo que existe uma relação de interdependência entre fenômenos particulares e a totalidade do social (Habermas, 1980, p. 282). Desse modo, Habermas tenta mostrar como a relação entre a teoria e a história depende da concepção de experiência que, hermeneuticamente falando, não pode ser dissociada do processo de construção teórica.

No quarto e último tema das diferenças - "a relação entre ciência e práxis transforma-se ao mesmo tempo em que a relação entre a teoria e a história" (Habermas, 1980, p.283), Habermas reflete sobre a importância do conhecimento vital para as ciências sociais, posto que os fenômenos sociais se dão em contextos históricos complexos, difíceis de serem amplamente alcançados pela ciência empírica que atua apenas como modo de explicação causal. A crítica aqui se refere ao fato de a sociologia empírico-analítica só poder obter previsões a partir de teorias específicas de acontecimentos recorrentes, sendo que fenômenos sociais não se dão em contextos recorrentes, eles se dão em contextos históricos, onde não cabe previsão ou determinação (Habermas, 1980, p. 284). É evidente que a crítica de Habermas à ciência empírico-analítica se deve à ausência de análise global, da noção de totalidade, um tema bastante recorrente na querela entre Popper e Adorno.

A epistemologia proposta pelo autor presume que a práxis pertence ao âmbito do dever ser, ao passo que o contexto em que as técnicas e aplicações empíricas se destinam pertence ao ser. Portanto, a proposta da ciência dialética não se limita à história, o ser; para a realização de uma práxis política é necessário ir além da visão contida na história, ir além das interpretações que 
foram estabelecidas, e libertar-se de determinações imanentemente científicas, as quais dispõem suas limitações à história.

Habermas encontra no método dialético maior aproximação entre ciência e práxis, tornando mais clara a dimensão política de sua teoria. A análise dialética da totalidade, do contexto real, permite contar com orientação científica para a ação prática. Tal capacidade atribuída ao método levou o autor a pensar sobre as possibilidades de a dialética "ultrapassar os limites da reflexão fundada na contrastabilidade" da ciência positiva, isto é, ultrapassar a técnica de verificação do real a partir de hipóteses e modelos pré-determinados. Trata-se de superar a falsa noção de universalidade do conhecimento, que fora construída pela participação direta da ciência empírico-analítica e da ciência hermenêutica. O autor se orienta pelas ideias de Adorno (cf. Adorno, 1986), a partir da vantagem e dever da ciência social dialética de criticar e de enfrentar seus próprios problemas, e nesse debate, concentra-se em verificar a influência de determinações sociais que condicionam a ciência.

As diferenças apresentadas também colocam em questão a neutralidade axiológica, que Popper defende em suas teses com o argumento da autonomia absoluta de leis naturais e de normas sociais. Estas são o conjunto de regras que regulamentam o comportamento humano, e aquelas correspondem aos fenômenos da natureza e da história com regularidades empíricas (Habermas, 1980, p. 286). Essa dualidade presente na tese de Popper fundamenta-se na diferenciação entre o social e o natural, decisão e conhecimento, dever ser e ser, normativo e descritivo. No âmbito do empírico, para usar termos de Habermas, evidenciam-se as normas sociais como valor e decisão, e as leis naturais como conhecimento, determinando um "dualismo entre decisões e fatos" independentes um do outro.

Um ponto importante a que Habermas chama atenção, de que "a dualidade entre fatos e decisões levar à validação do conhecimento fundado nas ciências da natureza e desta forma elimina-se a práxis vital do âmbito destas ciências" (Habermas, 1980, p. 287), revela o problema do método das ciências empíricoanalítica estar na eliminação de problemas práticos dos debates racionais. Ao fetichizar a ciência positiva, em seu projeto de uma "sociedade aberta" (cf. Popper, 1979), isto é, laica, Popper não renuncia à diferença entre valores e conhecimento; o conhecimento científico permanece sujeito a regras de uma metodologia universal. Habermas se refere à defesa racionalista de Popper como "profissão de fé", pois, ao desvincular o conhecimento da práxis, a razão limita-se à manipulação de regras lógico-formais do método, eliminando o caráter normativo da pesquisa e condicionando apenas a regularidades empíricas e ao comportamento técnico adequado. 
A pesar de reconhecer que Popper em certa medida apresenta uma vinculação entre a ciência empírica e o que chama de ciência dos valores (quando Popper recorre a formulações de Charles S. Peirce sobre conhecimento empírico e hábitos comportamentais), Habermas (1980, p. 291) considera que a proposta alternativa de Popper não lhe retirou o caráter positivista, uma vez que ele não conseguiu pensar a produção do conhecimento sem depender de hipóteses legais. Essa alternativa, segundo a crítica habermasiana, vincula modelo analítico-empírico e referencial vital do domínio concreto da natureza, - "uma integração anterior de percepções isoladas no contexto das convicções não problematizadas com amplo nível de credibilidade" (Habermas, 1980, p. 293) - um conjunto de normas socialmente construídas sobre as quais existe um consenso permitindo uma validação intersubjetiva, estabelece certo fundamento hermenêutico na pesquisa positiva.

A hermenêutica aparece como importante contribuição para compreender os problemas da ciência empírico-analítica, sobretudo para esclarecer o processo de construção dos sentidos de trabalho e dominação tecnológica, bem como os interesses evidenciados em todo esse processo social no qual essa ciência surge e se desenvolve. Em conformidade com o desenvolvimento da sociedade burguesa, a ciência empírica determina-se como forma prática do conhecimento mecanicista e torna-se amplamente aceita. Nas palavras de Habermas: "somente no quadro da sociedade moderna burguesa, legitimando a aquisição da propriedade pelo trabalho, poderia a ciência na área experimental receber um estímulo do trabalho manual e a pesquisa integrar-se progressivamente no trabalho social" (Habermas, 1980, p. 294).

No amplo contexto do capitalismo avançado, a neutralidade axiológica da ciência empírico-analítica revela-se de acordo com as necessidades do processo desenvolvido na sociedade burguesa. Com a objetividade dos enunciados válidos, a limitação do conhecimento se depara com problemas no âmbito da prática, os quais necessitam de muito mais que regras técnicas. Segundo Habermas, precisam de implicações do referencial vital e conteúdos concretos da imposição do mundo social em que habita o objeto e a própria pesquisa. Considerar a totalidade vital torna-se indispensável para superar as ilusões da ciência empírico-analítica de que nas ciências sociais é possível um controle idêntico ao das ciências naturais.

A reflexão sobre os interesses motivadores do processo de conhecimento leva à análise dialética, isto é, “à concepção da análise como parte integrante do processo social analisado, como sua consciência crítica possível” (Habermas, 1980 , p. 299), dedicando-se, entre outros temas, a pensar a racionalidade e suas formas de dominação no contexto capitalista. Os trabalhos de Habermas 
dedicados à análise da racionalização da técnica e da ciência enquanto elementos de validade no processo de desenvolvimento do modo de produção registram algumas das preocupações do autor no período que precede sua Teoria do agir comunicativo. Na sessão seguinte, apresento alguns pontos da crítica de Habermas à ciência empírico-analítica, buscando mostrar nos termos do autor como a racionalidade técnica e científica se torna uma forma de vida e de dominação.

\section{Da relação entre teoria e prática: técnica e ciência como ideologia}

Em Técnica e ciência como ideologia, Habermas (1983 [1968]) retoma a tese de Marcuse (cf. Marcuse, 1998) sobre a técnica e a ciência se transformarem em dominação política e econômica, e denuncia a estrutura e o progresso do projeto científico como ideológicos e dependentes de relações sociais de subordinação. E para além dessa tese, o autor avança com seu diagnóstico histórico do capitalismo tardio. No mesmo ano, Habermas também publicou Conhecimento e interesse. Nela o autor defende a autorreflexão epistemológica, que para ele deve ser crítica e emancipatória na reconstrução racional das condições universais da razão. Segundo McCarthy (1998, p. 62), Habermas deu continuidade a um projeto kantiano e trabalhou sua crítica ao positivismo enquanto ideia que relaciona conhecimento e ciência empírica, que resume filosofia do conhecimento em filosofia da ciência e elimina o sujeito cognoscente ao ocultar a base transcendental das ações e da experiência.

Bernstein (1994, p.28-29), em sua análise dos primeiros trabalhos de Habermas, enfatiza que em Conhecimento e interesse o autor defendeu a ideia de que as ciências sociais críticas, orientadas pelo interesse emancipatório, representam em certa medida uma síntese do conhecimento das ciências empíricas e das ciências hermenêuticas, no sentido de que a ciência crítica seria ao mesmo tempo empírica e interpretativa. A proposta de uma teoria reconstrutiva, tendo como fundamento nexos entre interesses cognitivos e formas de conhecimento (Habermas, 2014b, p. 23), levou o autor a tratar de diferentes e importantes campos do pensamento, de Kant a Freud, passando por Fichte, Hegel, Marx, Dilthey, Peirce, Nietzsche e Comte. Em nota, McCarthy (1998) cita as principais referências utilizadas por Habermas para cumprir com seu projeto de autocrítica do desenvolvimento do cientificismo. Na Alemanha, os principais autores foram Apel, Geigel, Kambartel, Schnädelbach, Tugendhat e Wellmer; o construcionismo da Escola de Erlangen; a controvérsia sobre a reconstrução racional da história da ciência, da qual participa Popper; e 
a filosofia linguística, passando por Wittgenstein, Austin, Searle e outros teóricos da pragmática.

Em Técnica e ciência como ideologia, o problema central diz respeito “à 'racionalização' progressiva da sociedade estar ligada à institucionalização do progresso científico e técnico. Na medida em que a técnica e a ciência penetram os setores institucionais da sociedade, transformando por esse meio as próprias instituições, as antigas legitimações se desmontam" (Habermas, 1983, p. 313). Tal problematização retoma a discussão anterior da ausência de referencial vital na construção do conhecimento e a predominância da racionalidade técnica apoiada na lógica empírico-analítica.

Visto que no capitalismo avançado predomina a racionalidade instrumental, que trata de meios adequados para atingir fins desejáveis, Habermas recorre ao conceito de racionalidade de Weber, a ação racionalcom-respeito-a-fins, concordando com a tese de Marcuse (1998) sobre a racionalidade técnica não revelar seu conteúdo político. É importante observar que esse ensaio marcou, pela primeira vez, a importância da teoria da ação de Max Weber nas formulações de Habermas sobre a sociedade capitalista e seu desenvolvimento, de modo que fornece elementos centrais de orientação do autor para pensar criticamente os limites do materialismo histórico de Karl Marx, assim como a reformulação do conceito de racionalização do próprio Weber. Essas propostas de Habermas são audaciosas e revelam suas diferenças em relação a seus precursores da Escola de Frankfurt. É certo que faltam registros bibliográficos para esclarecer as mudanças de posições de Habermas em relação a Adorno e Horkheimer, as quais tiveram suas primeiras aparições no conjunto de textos reunidos no mesmo livro. Desde então, a teoria da racionalização de Max Weber exerceu importante papel no rumo tomado por Habermas, que posteriormente teve sua forma mais acabada em Teoria do agir comunicativo. $^{8}$

O debate com os positivistas sobre teoria e práxis, que marcou o período do final dos anos de 1950 até o início dos 70, ocupou a Teoria Crítica com os temas dominação e politização da ciência, e passou, com a mudança de posição de Habermas, a dar lugar a uma teoria da ação e ao tema da democracia sob a perspectiva da emancipação. $\mathrm{O}$ duplo caráter da racionalidade permitiu a Habermas pensar sob a chave da interação, do trabalho e da linguagem, e

\footnotetext{
${ }^{8}$ Dos textos da década de 1960 até Teoria do agir comunicativo, Habermas apresentou muitas descontinuidades. Bersntein $(1994$, p. 35) atribui as mudanças de premissas analíticas ao constante debate que Habermas trava com seus críticos e com intelectuais contemporâneos, se permitindo identificar fragilidades em suas análises e a reformular conforme necessário, conservando apenas o que considera válido para o presente.
} 
não apenas a racionalidade técnica, instrumental, a qual Adorno e Horkheimer teriam ressaltado em Dialética do esclarecimento. Em outras palavras, o rumo tomado por Habermas priorizou a autonomia em detrimento da dominação.

Voltando para a tese de Marcuse, sobre aquilo que Habermas se utiliza, a racionalização weberiana acaba por ocultar sua forma de dominação política, reduzindo-se a simples corretivo do sistema, perdendo sua força enquanto racionalidade. Habermas afirma que a racionalização de Weber não é apenas um processo de modificação das estruturas sociais, mas é também a manutenção de uma dominação. Para ele (Habermas, 1983, p. 316): "“...] a racionalidade da ciência e da técnica já é, de modo imanente, uma racionalidade de manipulação, uma racionalidade de dominação". ${ }^{9}$

Considerando que o aparente bem-estar social esconde o teor político da razão técnica, Habermas passa a procurar compreender como essa racionalidade instrumental toma espaço nas relações da vida cotidiana, isto é, como ela se torna uma totalidade histórica. Para Marcuse, que foi o primeiro a registrar o processo de transformação das forças produtivas em elemento de legitimação da dominação, a saída possível estaria numa nova construção teórica e metodológica da ciência. Esta proposição é apontada por Habermas como fragilidade, pois o padrão de racionalidade permaneceria inalterado. Se quisermos traçar um paralelo, podemos tomar como exemplo as teses de Popper, que ele concebia como uma nova proposta metodológica, ao tentar superar as insuficiências do Círculo de Viena; não tendo feito com outros padrões de racionalidade, permanece o paradigma dos enunciados válidos e da necessidade de comprovação empírica, sem qualquer chance para fatos sociais isolados ou fora das regras previstas. Por essa experiência, torna-se evidente que a necessidade de superação da razão técnica e instrumental só será satisfeita quando a ação se utilizar de novos padrões de racionalidade, sem se submeter à ideologia da acumulação de capitais.

Concluindo que o desenvolvimento técnico obedece à lógica do agir racional-com-respeito-a-fins, e controlado pelo sucesso dos meios de produção, torna-se difícil renunciar a essa técnica enquanto a natureza humana permanecer a mesma (Habermas, 1983, p. 318). Nem Weber nem Marcuse teriam conseguido explicar o processo de racionalização ocidental. A busca por tal compreensão foi o que fez Habermas apresentar sua visão bidimensional da sociedade como característica própria da modernidade ocidental, e distinguir

\footnotetext{
${ }_{9}^{9}$ Sobre a expansão da racionalidade técnica, ver em Barbara Freitag (1986, p.96) importantes pontos tratados por Habermas em debate com Marcuse.
} 
trabalho e interação, destacando o interesse emancipatório, e seguindo com seu pensamento para as relações de intersubjetividade, que posteriormente viria a chamar de ação comunicativa.

Dispondo de dois tipos de ação racional, a ação comunicativa e a ação racional-com-respeito-a-fins, Habermas procurou reformular o conceito weberiano de racionalização, definindo cada dimensão social a partir do tipo de ação racional a que pertence. O quadro institucional do sistema de interação é formado por normas sociais, linguagem intersubjetiva, comportamentos recíprocos e de expectativas, sanções convencionais, interiorização de papéis sociais e um conjunto de manutenção das instituições, cuja racionalidade implica emancipação, ação comunicativa, e individuação. No sistema da ação estratégica impera a ação teleológica, o agir racional-com-respeito-a-fins. A ele pertencem regras técnicas, o trabalho, a linguagem independente do contexto, imperativos e prognósticos condicionais. Também faz parte a conquista de objetivos finais, cuja racionalidade implica o crescimento de forças produtivas e a ampliação do poder de manipulação técnica (Habermas, 1983, p. 322).

Com esses dados gerais é possível afirmar que o paradigma habermasiano, desde Técnica e ciência como ideologia, propõe uma nova forma de racionalização. Pela primeira vez na teoria social contemporânea, um teórico expôs uma concepção bidimensional do conceito de sociedade, superando os limites de teorias unilaterais. O método dialético e crítico permitiu a Habermas tratar simultaneamente da ação técnica - a validade das proposições empiricamente verdadeiras - e da ação comunicativa - a intersubjetividade de entendimento mútuo entre os indivíduos da interação, com base em reconhecimento universal dos valores. Toda essa capacidade do autor corresponde a uma síntese de teorias e debates no campo da Filosofia e da Sociologia, entre elas a querela entre Popper e Adorno. A extensão teórica e crítica de Habermas é tão grande, que para esta reflexão só me cabe a capacidade de pensar suas contribuições na disputa entre a ciência dialética e a ciência positivista. A reformulação do conceito weberiano de racionalização foi sem dúvida uma importante contribuição para tal, pois com ela Habermas identifica a sociedade capitalista pelo grau de contenção do agir racional-com-respeitoa-fins, isto é, quanto mais os subsistemas dessa racionalidade invadem valores e elementos típicos da tradição cultural, nos sistemas de interação, maior é a influência do agir instrumental estratégico sobre o agir comunicativo.

Em seu diagnóstico, a dominação da tradição, contida no sistema da interação como dominação política, foi substituída pela dominação justificada por relações legítimas de produção. Nesse contexto, a pressão racionalizante, isto é, o processo de coação do indivíduo a transferir habilidades da interação 
para habilidades do poder, resulta de dois tipos de racionalização distinguidas por Habermas e próprias da ação estratégica. A primeira corresponde à imposição do novo modo de produção, de maneira que os subsistemas da racionalidade instrumental ou estratégica se propagam por meio da organização do trabalho e da circulação econômica, passando por redes de informações e pela burocracia estatal, ocupando todos os setores da vida, incluindo instituições como a família, por exemplo. O outro tipo de racionalização, diretamente vinculado ao primeiro tipo, seria a perda de obrigatoriedade das tradições que legitimam e orientam a dominação. Equivale dizer que a legitimação do poder com base em valores tradicionais é substituída por uma nova legitimação, agora de caráter técnico e científico.

Para o modelo epistemológico habermasiano interessam as relações entre sujeitos, a intersubjetividade presente no sistema de interação, ou seja, não as relações entre sujeito e objeto. A crítica de Habermas ao programa de substitutivos se deve à exclusão de questões práticas de valores democráticos, uma vez que a solução de tarefas técnicas não depende de discussões públicas, intersubjetivas. Uma das contribuições de Habermas que se somam à tese de Marcuse está na concepção de estado moderno como articulador do processo de dominação dos sistemas do agir estratégico. A política estatal assume a função de eliminar riscos do sistema econômico, solucionando problemas técnicos e deixando de lado os problemas práticos, ela apresenta o desmoronamento da ideologia de troca justa, que caracteriza o quadro institucional das interações e assume, portanto, uma ideologia do progresso baseada na ação técnica. ${ }^{10}$

O diagnóstico do capitalismo tardio aponta para a desvinculação entre as leis econômicas e o movimento da sociedade. Nesse contexto, a sociedade aparece carente de autorregulação e com sua política na dependência da base econômica e do paradigma da ação técnica, cuja atuação impregna os diversos subsistemas da sociedade moderna, incluindo as interações intersubjetivas. Desse modo, as contradições sociais não se devem apenas aos antagonismos de classe, como defendera Marx. Elas também "resultam do processo de valorização do capital ao modo da economia privada"; da intensificação do programa de substitutivos resultou o trabalho como não sendo mais o único gerador de valor, sendo também o estado, a técnica em si e a própria sociedade, animados pela ideia de progresso (Habermas, 1983, p. 330).

\footnotetext{
${ }^{10}$ Habermas se utiliza de formulações de Claus Offe a respeito da relação entre economia e estado. OFFE, C. Zur Klassentheorie und Herrschaftsstruktur im staatlich regulierten Kapitalismus (manuscrito).
} 
Esse estado, cuja intervenção é distribuída desproporcionalmente, como o é com educação, saúde, e transporte, por exemplo, consegue, por meio de indenizações, garantir certa fidelidade da massa assalariada. Nesse contexto do capitalismo tardio, os conflitos e interesses de classes não são facilmente identificáveis, tratando-se de um processo de desvalorização do trabalho e de despolitização da população que, legitimada pela consciência tecnocrática e o velamento de questões práticas, elimina diferenças entre técnica e práxis, ferindo a linguagem e, de modo geral, a socialização e a individuação (Habermas, 1983, p. 335).

A crescente dependência das forças produtivas em relação ao processo técnico científico, enfraquece o potencial de emancipação. A ideologia tecnicista torna o quadro institucional vulnerável aos subsistemas do agir racional-com-respeito-a-fins, o qual se autonomiza tornando o processo histórico moderno uma tarefa técnica, sem a consciência da sociedade. Para Habermas, a única possibilidade de tornar as forças produtivas um potencial emancipatório estaria quando a razão comunicativa não fosse substituída pela razão técnica. Porém, o diagnóstico de realidade aponta justamente para o contrário. A adaptação passiva do quadro institucional "põe em xeque" a consciência de classe, que, em termos teóricos, leva Habermas a defender a emancipação pela via da discussão pública, com adequação de normas que orientem a ação. A saída estaria em princípios que não se submetessem à disciplina do trabalho alienado, ou ao modo de vida que fetichiza a ação técnica, pois a ideologia que legitima o capitalismo tardio é frágil, segundo o autor, e protegida essencialmente pela despolitização do domínio público.

\section{Considerações finais}

A preocupação com a racionalidade moderna e suas patologias é, sem dúvida, um fio condutor de toda a trajetória intelectual de Habermas. O debate positivista na sociologia alemã foi, de fato, importante para que o autor concretizasse com maior clareza sua teoria reconstrutiva buscando superar a dualidade entre ciências empíricas e ciências hermenêuticas. Passando pela teoria dos interesses cognitivos, pelo caráter político da produção do conhecimento científico e a ideia de uma comunidade crítica falível, bem como as relações intersubjetivas e sua noção bidimensional do conceito de sociedade, Habermas chega à sua virada linguística - da filosofia da consciência, centrada no indivíduo, para a filosofia da linguagem.

Sobre a fase específica que buscamos refletir, a tentativa de explorar diferenças entre a ciência empírico-analítica e a ciência dialética revela 
um problema epistemológico colocado por Habermas, que é a dualidade entre o conhecimento positivista, com base em comprovação empírica, e o conhecimento hermenêutico, com base na compreensão dos sentidos. Por essa lógica, a ciência social crítica, motivada pelo interesse emancipatório e orientada pela tentativa de reconstrução histórica dos nexos entre conhecimento e interesse, permite superar o dualismo do conhecimento entre positivismo e hermenêutica.

A ausência de crítica imanente faz da ciência um conhecimento ideológico que separa teoria e práxis. O contrário disso, e conforme busquei apresentar, as contribuições de Habermas para o debate epistemológico apontam para o caminho de uma ciência normativa. Resulta dessa concepção que teoria não se desvincula da totalidade social, pois o conhecimento e a forma de produzi-lo são possibilidades fornecidas pelo próprio contexto social; teoria, conceitos e outras categorias científicas devem se adequar ao objeto, e não o inverso; o material histórico, por sua vez, jamais deve ser determinado pelo conhecimento, visto que a interrelação entre fenômenos particulares e a totalidade histórica, ou, entre teoria e história, perpassa pela experiência; e a práxis, enquanto parte do conhecimento dialético, deve ultrapassar os limites da história, pois ela em nada se aproxima da técnica e de aplicações empíricas.

É importante considerar que nessa primeira fase de sua produção intelectual, Habermas considera a consciência do sujeito como intermediário para legalidades históricas - ponto este que ele não deu continuidade em sua Teoria do agir comunicativo. Mas independentemente de o autor ter alterado sua ênfase teórica, seu objetivo mais profundo permanece na busca pelos potenciais de emancipação. Inicialmente, em Teoria analítica da ciência e dialética, e logo em seguida, em Conhecimento e interesse, Habermas deu continuidade ao debate entre Popper e Adorno, onde tratou da negação da experiência pré-científica e reflexiva como problema a ser enfrentado pela teoria do conhecimento. Considerando que a orientação teórica não é descolada do processo social, a relação entre interesses socialmente construídos e a ciência só pode ser uma constatação da crítica imanente. Dando sequência a seu trabalho teórico crítico, Habermas encontra nas relações intersubjetivas capacidades da linguagem não exploradas e com potencial de superação e emancipação dos efeitos perversos da ideologia no contexto do capitalismo tardio. Sem deixar a perspectiva bidimensional da sociedade, dedica-se a um novo tema, que passa a ser central, o agir comunicativo, reafirmando sua oposição ao paradigma cientificista e buscando, no limite, aproximar pensamento crítico social e pesquisa. 


\section{Referências}

ADORNO, Theodor. Dialética negativa. Madrid: Taurus, 1975 [1965].

ADORNO, Theodor. Sobre a lógica das ciências sociais. In: Gabriel Cohn (Org.). Theodor W Adorno. São Paulo: Ática, 1986. p. 33-45. (Grandes Cientistas Sociais).

ADORNO, Theodor. Introdução à controvérsia sobre o positivismo na sociologia alemã. In: Textos Escolhidos. Coleção Os Pensadores. São Paulo: Abril Cultural, 1980. p. 209-257.

ADORNO, Theodor. Zur Logik der Sozialwissenschaften. Kölner Zeitschrift für Soziologie und Sozialpsychologie, v. 14, n. 2, p. 249-263, 1962.

BARRETO, Túlio V. Positivismo versus teoria crítica em torno de debate entre Karl Popper e Theodor Adorno acerca do método das ciências sociais. Perspectivas Filosóficas, v. 1, n. 15, p. 141-178, 2001.

BERNSTEIN, Richard. Introducción. In: Antony Giddens (Org.). Habermas y la modernidad. Madrid: Cátedra, 1994. p. 13-61.

DAHRENDORF, Ralf. Anotaciones a la discusíon de las ponencias de Karl Popper y T. W. Adorno. In: Ralf Dahrendorf (Org.). La disputa del positivismo a la sociologia alemana. Barcelona: Grijalbo. 1972 [1969]. p. 139-146.

FREITAG, Bárbara. A teoria crítica: ontem e hoje. São Paulo: Brasiliense, 1986.

GANEM, Angela. Karl Popper versus Theodor Adorno: lições de um confronto histórico. Revista de Economia Política, v. 32, n. 1, p. 87-108, $2012<10.1590 /$ S010131572012000100006>

GIDDENS, Anthony. A crítica do positivismo na filosofia de Frankfurt. In: Tom Bottomore (Org.). História da análise sociológica. Rio de Janeiro: Zahar, 1980. p. 344-351.

HABERMAS, Jürgen. Teoria analítica da ciência e dialética: contribuição à polêmica entre Popper e Adorno. In: Textos escolhidos. Walter Benjamin, Max Horkheimer, Theodor W. Adorno, Jürgen Habermas. São Paulo: Abril Cultural, 1980 [1965]. p. 277-299.

HABERMAS, Jürgen. Técnica e ciência como "ideologia". In: Textos escolhidos. Walter Benjamin, Max Horkheimer, Theodor W. Adorno, Jürgen Habermas. São Paulo: Abril Cultural, 1983 [1968]. p.313-343.

HABERMAS, Jürgen. Conhecimento e interesse. In: Técnica e ciência como “ideologia”. São Paulo: Editora Unesp, 2014a. p. 177-201.

HABERMAS, Jürgen. Positivismo, pragmatismo, historicismo. In: Conhecimento $e$ interesse. São Paulo: Editora Unesp, 2014b. p. 117-290.

HABERMAS, Jürgen. Contra un racionalismo menguado de modo positivista. In: Ralf Dahrendorf (Org.). La disputa del positivismo a la sociologia alemana. Barcelona: Grijalbo, 1972. p. 221-250.

HORKHEIMER, Max. Teoria tradicional e teoria crítica. In: Benjamin, Habermas, Horkheimer, Adorno. Textos escolhidos. São Paulo: Abril Cultural, 1983 [1937]. p. 117-154. 
KEUTH, Herbert. The positivist dispute in German sociology: a scientific or a political controversy? Journal of Classical Sociology. v. 15, n. 2, p. 154-169, 2015 $<10.1177 / 1468795 X 14567825>$.

MARCONDES, Danilo. Iniciação à história da filosofia: dos pré-socráticos a Wittgenstein. Rio de Janeiro: Jorge Zahar, 1998.

MARCUSE, Herbert. A industrialização e o capitalismo na obra de Max Weber. In: Herbert Marcuse. Cultura e Sociedade, v. 2, São Paulo: Paz e Terra, 1998. p. 113-136.

McCARTHY, Thomas. La teoría crítica de Jürgen Habermas. Madrid. Editorial Tecnos, 1998.

PASQUINELLI, Alberto. Carnap e o Positivismo Lógico. Lisboa: Edições 70, 1983.

POPPER, Karl. R. Lógica das ciências sociais. In: Karl Popper. Lógica das Ciências Sociais. Brasília: Editora Universidade de Brasília, 1978a, p. 13-34.

POPPER, Karl. R. Razão ou revolução? In: Karl Popper. Lógica das Ciências Sociais. Brasília: Editora Universidade de Brasília, 1978b. p.35-49.

POPPER, Karl R. La societé ouverte et ses ennemis. Paris: Éditions du Seuil, 1979.

SAUER, Werner. Circulo de Viena. In: W. Outhwaite (Org.). Dicionário do pensamento social do século XX. Rio de Janeiro: Jorge Zahar, 1996. p. 799-803.

SCHUTZ, Alfred. Collected papers. Den Haag: Nijhoff Verlag, 1962.

Recebido em: 1ํㅡ. mar. 2017

Aprovado em: 7 jul. 2017

Autora correspondente:

Rubia de Araujo Ramos

Rua Cora Coralina, 100 - Barão Geraldo

13083-896 Campinas, SP, Brasil 